Vol. 5 No. 2, February 2022, Pages 127-138 http://e-journal.unipma.ac.id/index.php/doubleclick

\title{
Perancangan Tata Kelola Teknologi Informasi dengan Menggunakan Framework Cobit 2019 pada PT XYZ Balikpapan
}

\author{
Endah Wulandari ${ }^{1}$, Lovinta Happy Atrinawati ${ }^{2}$, M. Gilvy Langgawan Putra \\ ${ }^{1,2,3}$ Program Studi Sistem Informasi, Institut Teknologi Kalimantan \\ email: 10171024@student.itk.ac.id
}

\begin{abstract}
PT XYZ Balikpapan provides various services, namely testing and analysis services, assessment and auditing, training and certification in various fields. Regarding the use of information technology that does not work well, it has an impact on optimizing the implementation of business goals and has an impact on threats related to information technology. As a result, management is using the COBIT 2019 framework to help businesses achieve their desired goals. Steps of designing an information technology manager based on the COBIT 2019 framework with interviews to learn more about the company and its strategies. Next, define the initial scope of the administration system. Increase the scope of system administration, improve governance design, evaluate process capabilities, prepare improvement proposals, and develop improvement recommendations findings. The value at the capability level is carried out which has a value greater than equal to 75 , the target capability level is at level 4. It was found that a very important process at PT XYZ Balikpapan has a capability level at level 1 APOO9 Managed Service Agreements, APO12 Managed Risk, APO13 Managed Security, and DSSO2 Managed Service Requests \& Incidents. All processes that evaluate skill levels fail to reach capability levels. Therefore, all activities during the process were carried out and resulted in recommendations for improvement. The first is the APO09 core model in the future capacity requirements analysis document, service level agreement and service catalog in order to get an increase in the company's performance output in serving customers at PT XYZ Balikpapan.
\end{abstract}

Keywords: COBIT 2019, PT XYZ Balikpapan, information technology governance

\begin{abstract}
Abstrak: PT XYZ Balikpapan menyediakan berbagai layanan, yaitu layanan pengujian dan analisis, penilaian dan audit, pelatihan dan sertifikasi di berbagai bidang. Terkait pemanfaatan teknologi informasi yang tidak berjalan dengan baik, berdampak pada optimalisasi pelaksanaan tujuan bisnis dan berdampak pada ancaman terkait teknologi informasi. Akibatnya, manajemen menggunakan kerangka kerja COBIT 2019 untuk membantu bisnis mencapai tujuan yang diinginkan. Langkah-langkah merancang manajer teknologi informasi berdasarkan kerangka COBIT 2019 dengan wawancara untuk mempelajari lebih lanjut tentang perusahaan dan strateginya. Selanjutnya, tentukan ruang lingkup awal sistem administrasi. Meningkatkan cakupan administrasi sistem, menyempurnakan desain tata kelola, mengevaluasi kapabilitas proses, menyiapkan proposal perbaikan, dan mengembangkan temuan rekomendasi perbaikan. Nilai pada tingkat kapabilitas dilakukan yang memiliki nilai lebih besar dari sama dengan 75 , tingkat target kapabilitas pada level 4. Ditemukan proses yang sangat penting pada PT XYZ Balikpapan memiliki tingkat kapabilitas di level 1 APO09 Managed Service Agreements, APO12 Managed Risk, APO13 Managed Security, dan DSS02 Managed Service Requests \& Incidents. Semua proses yang mengevaluasi tingkat keterampilan gagal mencapai tingkat kapabilitas. Oleh karena itu, semua kegiatan selama proses dilakukan dan menghasilkan rekomendasi untuk perbaikan. Pertama yaiyu core model APO09 pada dokumen analisis kebutuhan kapasitas mendatang, service level agreement dan service catalog supaya mendapatkan meningkatkan output kinerja perusahaan dalam melayani pelanggan pada PT XYZ Balikpapan.
\end{abstract}

Kata kunci: COBIT 2019, PT XYZ Balikpapan, tata kelola teknologi informasi 


\section{Pendahuluan}

Di era globalisasi, teknologi informasi berpartisiasi dalam hampir semua kegiatan bisnis tradisional. Saat ini, teknologi informasi memegang peranan yang sangat penting dalam perusahaan jasa inspeksi dan audit. Untuk mendukung proses bisnis sebagai alat, TI secara khusus berperan dalam desain, pengembangan dan pengiriman infrastruktur, manufaktur, perdagangan, dan transportasi di bidang pertanian, manufaktur, batu bara dan mineral, minyak dan gas, dan pemerintahan (Azara, 2020).

Berdasarkan peran yang dapat dimainkan oleh teknologi informasi dalam mendukung proses bisnis di perusahaan. Oleh karena itu, tata kelola TI diperlukan untuk melakukan penilaian terhadap semua teknologi informasi yang ada di perusahaan. Administrator TI dapat memandu dan mengelola keputusan terkait TI dalam suatu perusahaan untuk mencapai tujuan atau sasaran yang diinginkan. Tujuan tata kelola TI adalah untuk memaksimalkan manfaat penggunaan teknologi informasi dan membantu mengelola risiko TI (Alreemy et al., 2016).

Tata kelola adalah hasil pengmbilan keputusan tentang kegiatan di perusahaan (Richardus Eko Indrajit, 2014), (Tri Oktarina, 2017), (Prasetyo \& Mariana, 2011). Tata kelola TI sangat penting bagi perusahaan untuk menjaga agar TI tetap sesuai dengan tujuan sehingga tujuan bisnis dapat tercapai (Novita Anastasia \& Happy Atrinawati, 2020), (Mariatama, 2021).

Dapat dilihat bahwa konsep tata kelola TI telah dibuat oleh beberapa penelitian sebelumnya. Pencarian pertama dengan judul "Perancangan Tata Kelola Teknologi Informasi pada Dinas Kesehatan Kabupaten Jepara" menggunakan framework COBIT 4.1 yang dilatarbelakangi bahwa sistem informasi yang dikelola oleh Dinas Kesehatan Kabupaten Jepara mengalami perubahan lebih baik pada bidang software, hardware, dan kemampuan petugas (Wahono, 2015).

Akan tetapi, faktanya tata kelola teknologi informasi dapat dikatakan belum berhasil diterapkan. Penelitian Selanjutnya dengan judul "Evaluasi terhadap Tata Kelola Teknologi Informasi dengan menggunakan COBIT 5 yang dilakukan di Badan Pendapatan Daerah Kabupaten Badung" bahwa telah ada penerapan teknologi informasi menggunakan Sistem Informasi dan Manajemen Objek Pajak (SISMIOP) (Sinta et al., 2019). Namun, masih terdapat beberapa kendala walaupun sistem yang gunakan sudah terintegrasi dengan baik.

Berdasarkan

penelitian sebelumnya, salah satu contoh perusahaan yang membutuhkan tata kelola TI adalah PT XYZ Balikpapan. PT XYZ Balikpapan memiliki visi yaitu menjadi perusahaan kelas dunia yang mampu bersaing, amanah dan terpercaya dalam bidang inspeksi, pengujian, sertifikasi, konsultasi dan pelatihan.

Dari sistem informasi tersebut terdapat kendala yang dihadapi PT XYZ Balikpapan dalam menggunakan sistem informasi tersebut. Keterbatasan antara lain sistem informasi simlab tidak digunakan secara optimal. Karena sistem informasi ini masih menggunakan versi lama. Jadi, selama pelacakan dokumen di lab, terjadi kesalahan saat memuat dokumen. Oleh karena itu, pengguna menindaklanjuti secara manual.

Dalam tata kelola TI, ada kerangka kerja yang bertindak sebagai panduan. ITIL mencakup layanan pelanggan, ISO mencakup kualitas organisasi atau ukuran kinerja, sedangkan COBIT berfokus pada manajemen teknologi informasi (Karkoskova \& Feuerlicht, 2015). COBIT memiliki cakupan konten yang sudah ada di kerangka kerja lain (Miranti, 2019), (Solehuddin et al., 2021).

Di COBIT 4.1, ada 4 domain. Di 4 area tersebut terdapat 34 proses yang masing-masing memiliki peran untuk 
melakukan aktivitas dan tanggung jawab, karena keproses tersebut tidak perlu digunakan, sesuai dengan kebutuhan perusahaan (IT Governance Institute (ITGI), 2007). Sementara itu, COBIT 5 dan COBIT 2019 membawa perubahan besar ketika ada 5 domain (ISACA, 2018). Namun terdapat perbedaan antara COBIT 5 dan COBIT 2019, pada COBIT 5 terdapat 37 core model, sedangkan pada COBIT 2019 terdapat 40 core model, terdapat 3 core model lagi versi COBIT 5.

COBIT 2019 dianggap sebagai framework terbaik dalam hal pengembangan manajemen TI dan fleksibel. Dan ketika menerapkan COBIT 2019, kami menganggapnya lebih relevan dengan situasi saat ini dan menerapkannya di seluruh organisasi. COBIT 2019 juga mendukung fleksibilitas penilaian berdasarkan faktor konstruktif (ISACA, 2018). COBIT juga menambahkan transformasi baru atau domain minat yang sudah ada tetapi tidak secara langsung mempengaruhi struktur dan ukuran model dasar di COBIT, dengan penambahan domain peningkatan konten baru dari versi COBIT sebelumnya. Inilah sebabnya mengapa PT XYZ Balikpapan menggunakan kerangka kerja COBIT 2019 untuk melakukan penelitian, memecahkan masalah dengan cara yang paling fleksibel, dan menyelaraskan implementasi TI dengan tujuan bisnis.

\section{Metode}

Secara garis besar, penelitian ini akan mencapai beberapa langkah yang teridentifikasi dalam desain dan desain sistem tata kelola, menentukan ruang lingkup awal sistem tata kelola, meningkatkan ruang lingkup sistem tata kelola, dan Menyelesaikan desain sistem manajemen. Langkah selanjutnya adalah menilai tingkat keterampilan desain manajemen. Langkah terakhir adalah membuat rekomendasi untuk memperbaiki studi kasus. Berikut adalah diagram survei untuk PT XYZ Balikpapan (ISACA, 2019).

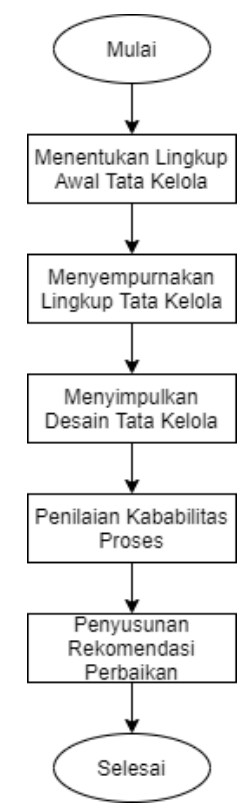

Gambar 1. Wireframe menu

Pada Gambar 1, elemen design factor 1 sampai 4 dianalisis sesuai ketentuan framework COBIT 2019 saat menentukan ruang lingkup awal tata kelola, Ini bisa menjadi tujuan perusahaan, masalah terkait teknologi informasi serta risiko yang memungkinkan terjadi pada perusahaan (Maulana Fikri et al., 2020), (Belo et al., 2020), (Supangat et al., 2022). Selanjutnya, kami mengajukan pertanyaan dan melakukan wawancara untuk mendapatkan penilaian terdapat pada design factor 1 sampai 4.

Dalam meningkatkan ruang lingkup pada sistem tata kelola, perlu dilakukan perbaikan lingkup sistem tata kelola dengan menangani elemen design factor 5 sampai 11 berdasarkan framework COBIT 2019 terkait dengan ancaman yang dihadapi perusahaan, tuntutan dalam peraturan atau persyaratan, peran teknologi informasi, model sumber daya teknologi informasi, metode yang dipilih untuk melakukan pengembangan teknologi informasi, strategi yang dilakukan untuk 
pemanfaatan teknologi informasi dapat optimal, serta melakukan pengukuran pada perusahaan (Bayastura et al., 2021).

Pada menyimpulkan desain tata kelola, dilakukan kesimpulan dari seluruh penilaian design factor yang telah dilakukan. Dari hasil kesimpulannya, didapatkan tingkat kapabilitas dari setiap core model. Proses yang dianggap penting adalah yang memiliki tingkat kapabilitas tertinggi level 4 dengan memiliki nilai $\geq 75$.

Penilaian kapabilitas proses menggunakan pengukuran berdasarkan COBIT 2019 untuk melakukan penilaian kapasitas. Pada fase ini, penilaian kapabilitas proses hanya pada dilakukan untuk proses dengan target capability level 4, hal ini dikarenakan keterbatasan waktu dan target capability level 4 penelitian ini dianggap sebagai proses yang penting.

Pada penyusunan rekomendasi perbaikan, dilakukan penyusunan rekomendasi perbaikan. Untuk memberikan saran perbaikan, hasil harus diperoleh berdasarkan penilaian pada tingkat kapabilitas dari setiap proses. Dari hasil evaluasi, dapat melihat pencapaian tingkat kapabilitas yang ingin dicapai, setelah itu dapat menyusun rekomendasi perbaikan untuk perusahaan agar dapat menerapkan rekomendasi yang diberikan untuk mencapai tingkat kapabilitas dan peningkatan level kematangan proses.

\section{Hasil dan Pembahasan}

Berdasarkan penelitian yang berjudul Perancangan Tata Kelola Teknologi Informasi Menggunakan Framework COBIT 2019 di PT XYZ Balikpapan, dapat ditarik temuan dan pembahasan. Tentukan ruang lingkup tata kelola awal, Tingkatkan ruang lingkup sistem tata kelola, Akhiri desain tata kelola, Evaluasi kemampuan proses dan Buat rekomendasi untuk perbaikan.
Menentukan lingkup awal tata kelola Design factor 1 (enterprise strategy) menjelaskan strategi perusahaan dengan PT XYZ Balikpapan berdasarkan empat strategi yang disediakan oleh framework COBIT 2019. PT XYZ Balikpapan memiliki strategi primer yang berfokus pada client service/stability, sehingga diberikan nilai tingkat kepentingan sebesar 5. PT XYZ Balikpapan juga memiliki strategi sekunder yaitu perencanaan kedua yang berfokus pada growth/acquisition dengan diberi nilai tingkat kepentingan sebesar 4, dimana perusahaan ini dalam aktivitasnya banyak menekankan pada pengelolaan keuntungan perusahaan. Sehingga, untuk Design Factor 1 dapat dilihat seperti berikut.

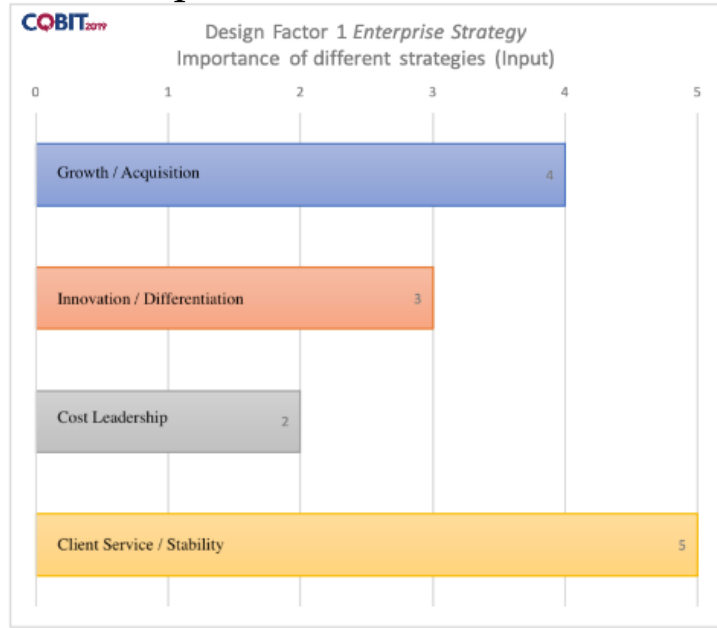

\section{Gambar 2.Design Factor 1}

Pada gambar 3 menampilkan hasil design factor 2 (enterprise goals). Adapun angka 1-5 dari gambar diatas merupakan penilaian pada tingkat kepentingan dari jenis tujuan perusahaan. Pada nilai 1 dipercaya taraf kepentingannya sangat rendah, nilai 2 dipercaya rendah, nilai 3 cukup, nilai 4 dipercaya tinggi, dan nilai 5 dipercaya sangat tinggi PT XYZ Balikpapan memiliki fokusan pada EG04 Quality of financial information, EG05 Customer-oriented service culture, dan EG12 Managed digital transformation programs, sehingga 
diberikan nilai tingkat kepentingan sebesar 5 .

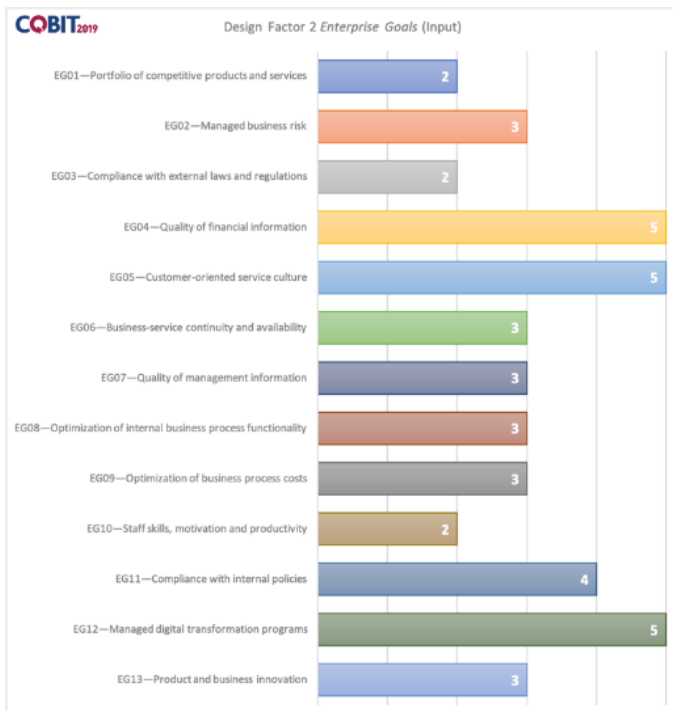

Gambar 3.Design Factor 2

Pada gambar 4 menampilkan hasil penilaian likelihood dan impact dari design factor 3 (risk profile). Adapun angka 0-25 dari gambar diatas merupakan nilai rata-rata dari tingkat kepentingan risiko terhadap TI. PT XYZ Balikpapan memiliki bentuk risiko TI yang paling tinggi, dengan nilai 20 yaitu pada Logical attacks (hacking, malware, etc.) dengan nilai likelihood 4 dan impact 5.

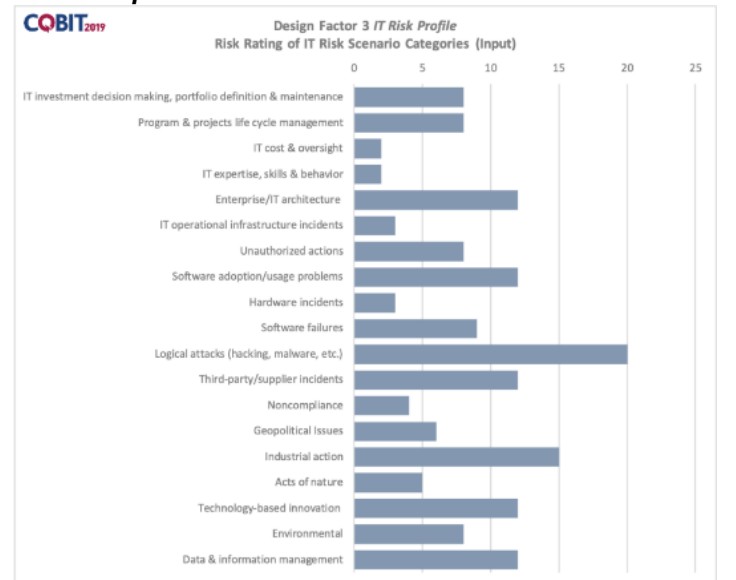

Gambar 4.Design Factor 3

Pada Gambar 5 menampilkan hasil penilaian tingkat kepentingan dari design factor 4 (I\&T-related issues). Adapun angka 0-3 dari gambar diatas merupakan penilaian pada tingkat kepentingan dari isu terhadap
TI. Pada nilai 1 dianggap tingkat kepentingannya bukan sebuah masalah, nilai 2 dianggap masalah, dan nilai 3 dianggap masalah yang serius.

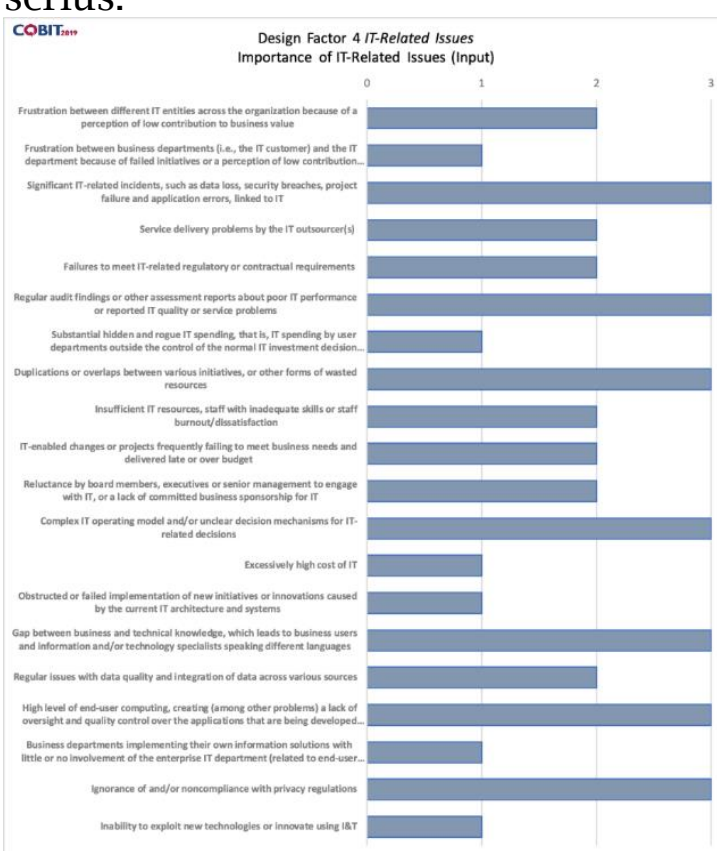

Gambar 5.Design Factor 4

Menyempurnakan lingkup sistem tata kelola

Pada Gambar 6 menampilkan hasil penilaian tingkat kepentingan dari design factor 5 (Threat Landscape) dalam bentuk persentase. PT XYZ Balikpapan memiliki nilai yang sama sebesar $50 \%$ pada tingkat ancaman normal dan high. Perusahaan ini biasanya menghadapi ancaman normal apabila terdapat kelalaian karyawan dalam melakukan tugas yang dapat mempengaruhi jalannya proses bisnis perusahaan.

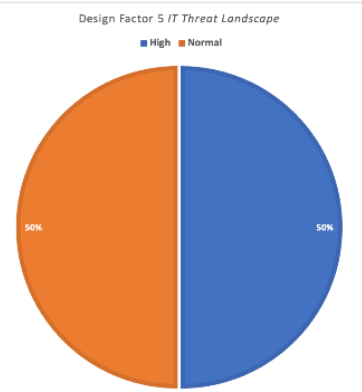

Gambar 6.Design Factor 5 
Pada Gambar 7 menampilkan hasil penilaian tingkat kepentingan dari design factor 6 (Compliance Requirement) dalam bentuk persentase. PT XYZ Balikpapan memiliki nilai paling tinggi sebesar 70\% pada jenis kepatuhan peraturan tingkat normal, dimana PT XYZ Balikpapan patuh terhadap peraturan di bidang insdustri. Pada kantor cabang Balikpapan mengikuti sektor industri terkait migas dan batu bara, sehingga peraturan yang diterapkan berkaitan dengan lingkungan bisnis yang ada di Balikpapan dan disesuaikan dengan peraturan BUMN.

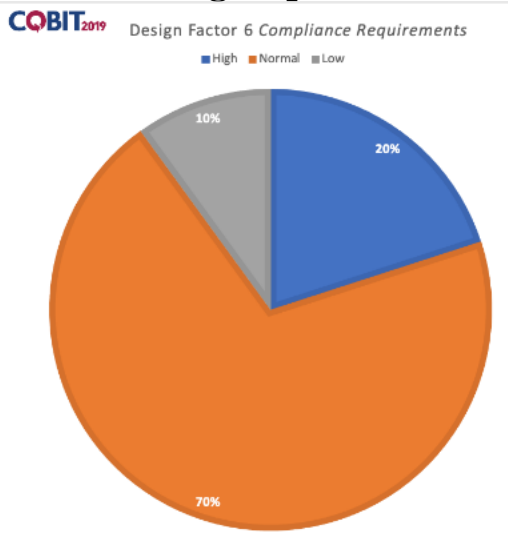

\section{Gambar 7.Design Factor 6}

Pada Gambar 9 menampilkan design factor 7 (role of IT). Adapun angka 1-5 dari gambar diatas merupakan penilaian pada tingkat pengaruh dari peran TI. Pada nilai 1 dianggap sangat tidak terpengaruh, nilai 2 dianggap tidak terpengaruh, nilai 3 dianggap cukup terpengaruh, nilai 4 dianggap terpengaruh, dan nilai 5 dianggap sangat terpengaruh. PT XYZ Balikpapan memiliki peran TI primer yang berfokus sebagai turnaround yang merupakan pendukung dalam proses inovasi, sehingga diberikan nilai tingkat pengaruh sebesar 5 .

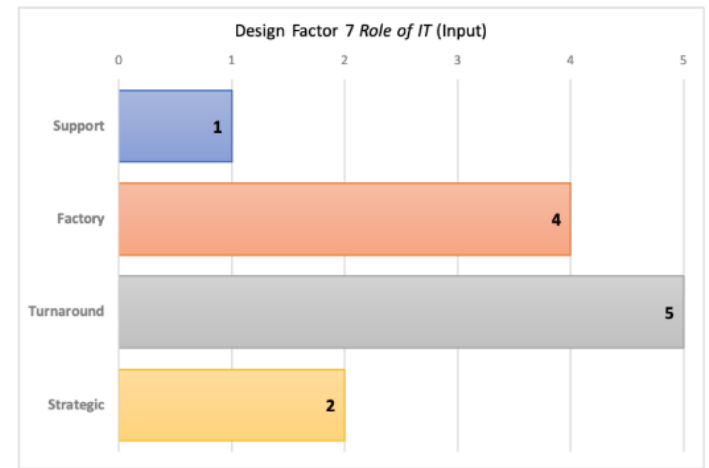

Gambar 8.Design Factor 7

Pada Gambar 9 menampilkan hasil penilaian tingkat kepentingan dari design factor factor 8 (Sourching Model of IT). PT XYZ Balikpapan memiliki nilai 50\% pada jenis pemodel TI outsourcing dan cloud, dimana pada kantor cabang Balikpapan merupakan pengguna layanan sistem dari kantor pusat. PT XYZ Balikpapan tidak memiliki wewenang dalam mengadakan atau menyediakan layanan TI, sehingga semua berkaitan dengan TI telah diatur oleh kantor pusat. Oleh karena itu, jenis penerapan TI pada outsourcing dan cloud berasal dari kantor pusat XYZ Jakarta.

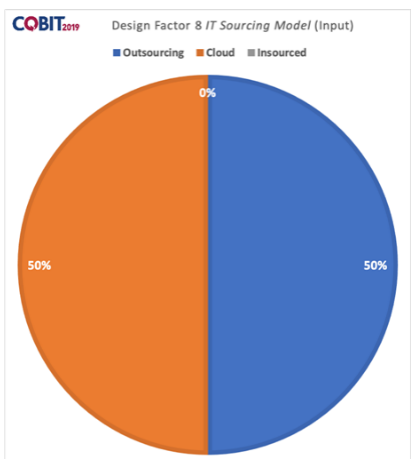

\section{Gambar 9.Design Factor 8}

Pada Gambar 10 menampilkan hasil penilaian tingkat kepentingan dari design factor factor 9 (IT Implementation Methods). PT XYZ Balikpapan memiliki nilai $80 \%$ pada jenis penerapan metode TI yaitu metode traditional. Hal ini dikarenakan PT XYZ Balikpapan merupakan kantor cabang, sehingga dalam kegiatan pengadaan dan pengembangan sistem merupakan 
sepenuhnya wewenang dari kantor pusat.

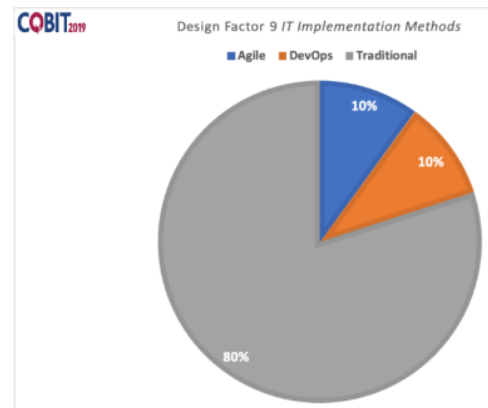

Gambar 10.Design Factor 9

Pada gambar 11 menampilkan hasil penilaian tingkat kepentingan dari design factor factor 10 (Technology Adoption Strategy). PT XYZ Balikpapan memiliki nilai 60\% pada kategori follower dan $40 \%$ pada kategori slow adopter. PT XYZ Balikpapan merupakan kantor cabang ketika mengambil teknologi baru perlu persetujuan dari kantor pusat. Sehingga, apabila terdapat teknologi baru, PT XYZ Balikpapan termasuk perusahaan yang lambat dalam mengambil teknologi baru.

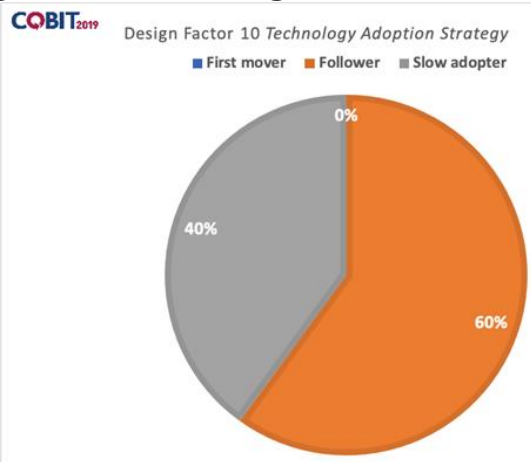

Gambar 11.Design Factor 10

Dalam menentukan Design Factor 11 dapat dilihat kriteria jumlah karyawan yang terdapat diperusahaan berdasarkan COBIT 2019. Jenis perusahaan yang termasuk perusahaan large merupakan perusahaan yang memiliki jumlah karyawan lebih dari 250 karyawan. Sedangkan perusahaan yang memiliki jumlah karyawan 50 hingga 250 karyawan, dapat dikategorikan jenis perusahaan small and medium . Berdasarkan hasil wawancara dengan
Bidang Dukungan Bisnis, perusahaan XYZ Balikpapan termasuk perusahaan small and medium dengan memiliki jumlah karyawan sebanyak 130 karyawan.

Menyimpulkan desain tata kelola

Pada gambar 12 merupakan kesimpulan ruang lingkup sistem tata kelola pada PT XYZ Balikpapan. Dimana, core model yang memiliki prioritas paling tinggi yaitu nilai $\geq 75$ dengan tingkat harapan pada level 3 dan level 4. Berdasarkan tabel 4.2 yang merupakan prioritas untuk dapat dilakukan penilaian kapabilitas proses yaitu pada core model APO09 (Managed Service Agreements) sebesar 100, APO12 (Managed Risk) sebesar 85, APO13 (Managed Security) sebesar 95, dan DSS02 (Managed Service Requests \& Incidents) sebesar 75.

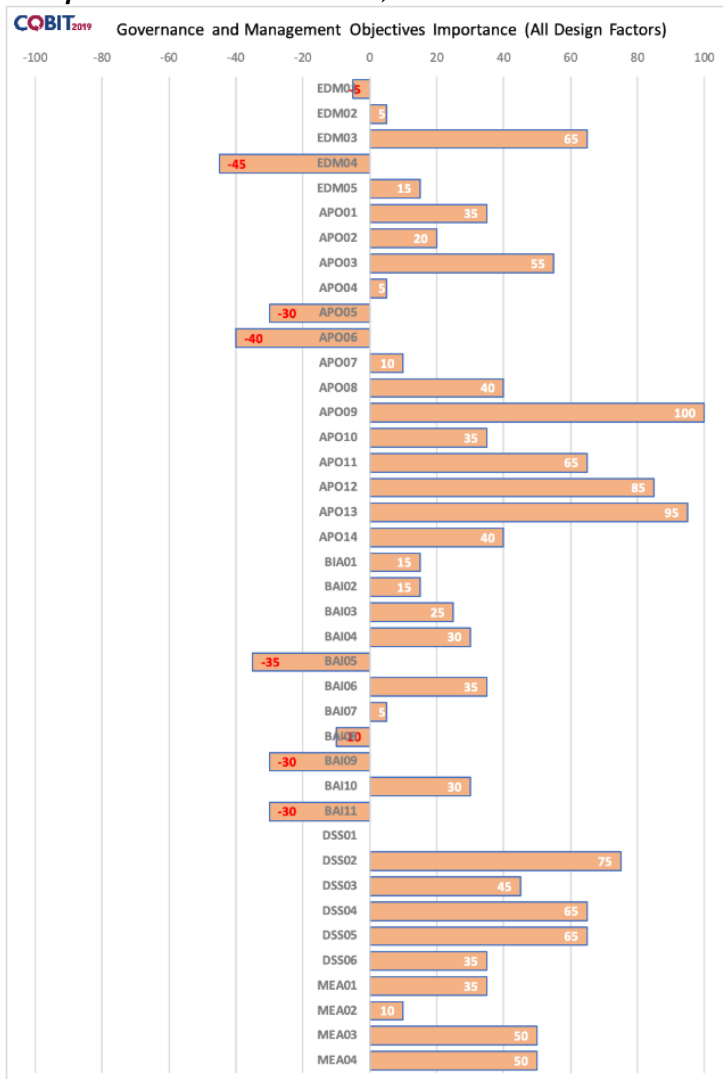

Gambar 12.Kesimpulan Desain

Penilaian kapabilitas proses

\begin{tabular}{|c|c|c|}
\hline Pada & core & APO09 \\
\hline (Managed & Service & Agreement \\
\hline beberapa & aktivitas & yang \\
\hline
\end{tabular}


yaitu menilai layanan I\&T dan tingkat layanan saat ini, menganalisis, mempelajari, serta memperkirakan permintaan di masa yang akan datang dan mengonfirmasi kompetensi layanan yang mendukung I\&T yang ada, mempublikasi dalam katalog layanan yang relevan dengan I\&T aktif, paket layanan, dan opsi tingkat layanan dari portofolio, membuat draf perjanjian layanan pelanggan, dan menyelesaikan perjanjian layanan pelanggan dengan manajemen hubungan bisnis. Aktivitas-aktivitas yang telah dijalankan merupakan hasil dari wawancara dengan Admin Officer 2 PT XYZ Balikpapan.

$$
\begin{gathered}
\text { Tingkat Kemampuan }=\frac{5}{\epsilon} \times 100 \% \\
\text { Tingkat Kemampuan }=83 \%
\end{gathered}
$$

Berdasarkan perhitungan proses kapabilitas diatas, core model APO09 (Managed Service Agreements), diperoleh hasil bahwa PT XYZ Balikpapan hanya menjalankan aktivitas sebanyak 5 dari 6 aktivitas Hal ini menunjukkan bahwa core model APO09 (Managed Service Agreements) tidak mencapai pada tingkat kapabilitas level 2. Dapat disimpulkan bahwa core model APO09 hanya mencapai level 1 .

Pada core model APO12 (Managed Risk), beberapa aktivitas yang telah dilakukan oleh PT XYZ Balikpapan yaitu Menetapkan serta menganalisis data terkait risiko TI, mencatat data terkait risiko I\&T yang relevan dan signifikan, melakukan inventarisasi proses bisnis dan dokumentasikan ketergantungannya pada bagian yang berperan sebagai tata kelola layanan TI dan pengadaan terkait sumber daya infrastruktur TI, memilih dan menyepakati layanan I\&T, dan memelihara inventarisasi kegiatan pengendalian yang ada guna memitigasi risiko. Aktivitas-aktivitas yang telah dijalankan merupakan hasil dari wawancara dengan Admin Officer 2 PT XYZ Balikpapan

$$
\begin{gathered}
\text { Tingkat Kemampuan }=\frac{5}{\epsilon} \times 100 \% \\
\text { Tingkat Kemampuan }=83 \%
\end{gathered}
$$

Berdasarkan perhitungan proses kapabilitas diatas, core model APO12 (Managed Risk), diperoleh hasil bawah PT XYZ Balikpapan hanya menjalankan aktivitas sebanyak 5 dari 6 aktivitas pada tingkat kapabilitas level 2. Sehingga, hasil perhitungan pada core model APO12 (Managed Risk) mendapatkan nilai sebesar 83\% yang artinya largely achieved. Hal ini menunjukkan bahwa core model APO12 (Managed Risk) tidak mencapai pada tingkat kapabilitas level 2, sehingga tidak dapat dilanjutkan ke tahap selanjutnya. Dapat disimpulkan bahwa core model APO12 hanya mencapai level 1.

Pada coremodel APO13 (Managed Security), beberapa aktivitas yang telah dilakukan oleh PT XYZ Balikpapan yaitu menentukan area dan batasan sistem manajemen keamanan informasi (ISMS), menentukan ISMS sesuai dengan kebijakan perusahaan, menyelaraskan ISMS dengan pendekatan perusahaan, menetapkan dan menghubungkan peran dan tanggung jawab manajemen keamanan informasi, melakukan komunikasi strategi ISMS. Aktivitas-aktivitas yang telah dijalankan merupakan hasil dari wawancara dengan Admin Officer 2 PT XYZ Balikpapan.

$$
\begin{gathered}
\text { Tingkat Kemampuan }=\frac{5}{7} \times 100 \% \\
\text { Tingkat Kemampuan }=72 \%
\end{gathered}
$$

Berdasarkan perhitungan proses kapabilitas diatas, core model APO13 (Managed Security), diperoleh hasil bawah PT XYZ Balikpapan hanya menjalankan aktivitas sebanyak 5 dari 7 aktivitas pada tingkat kapabilitas level 2. Sehingga, hasil perhitungan pada core model APO13 (Managed Security) mendapatkan nilai sebesar $72 \%$ yang artinya largely achieved. Hal ini menunjukkan bahwa core model APO13 (Managed Security) tidak 
mencapai pada tingkat kapabilitas level 2, sehingga tidak dapat dilanjutkan ke tahap selanjutnya. Dapat disimpulkan bahwa core model APO13 hanya mencapai level 1.

Pada coremodel DSS02 (Managed Service Requests \& Incidents), beberapa aktivitas yang telah dilakukan oleh PT XYZ Balikpapan yaitu mencatat semua permintaan dan insiden layanan, mendapatkan persetujuan atau persetujuan finansial dan fungsional, mencatat dan menjelaskan tandatanda yang signifikan untuk menetapkan penyebab dari kejadian yang mungkin terjadi, mencatat masalah yang terjadi ketika belum adanya solusi dari masalah tersebut, menetapkan insiden ke fungsi spesialis jika diperlukan keahlian yang lebih dalam, memilih serta menerapkan resolusi insiden yang paling tepat, mencatat apabila solusi diterapkan untuk keputusan kejadian, melakukan aktivitas pemulihan, mendokumentasikan keputusan kejadian dan nilai apakah resolusi tersebut dapat digunakan sebagai referensi untuk kedepannya, mendokumentasikan kesimpulan kejadian dan nilai apakah kesimpulan tersebut dapat diterapkan sebagai sumber pengetahuan di masa depan, memeriksa ulang dengan pengguna terhadap keinginan layanan yang ingin dipenuhi dengan memuaskan atau insiden dan minta prosedur penanganan. Aktivitas-aktivitas yang telah dijalankan merupakan hasil dari wawancara dengan Admin Officer 2 PT XYZ Balikpapan.

$$
\begin{gathered}
\text { Tingkat Kemampuan }=\frac{11}{15} \times 100 \% \\
\text { Tingkat Kemampuan }=73 \%
\end{gathered}
$$

Berdasarkan perhitungan proses kapabilitas diatas, core model DSS02 (Managed Service Requests \& Incidents), diperoleh hasil bawah PT XYZ Balikpapan hanya menjalankan aktivitas sebanyak 11 dari 15 aktivitas pada tingkat kapabilitas level 2. Sehingga, hasil perhitungan pada core model DSS02 (Managed Service Requests \& Incidents) mendapatkan nilai sebesar 73\% yang artinya largely achieved. Hal ini menunjukkan bahwa core model DSSO2 (Managed Service Requests \& Incidents) tidak mencapai pada tingkat kapabilitas level 2, sehingga tidak dapat dilanjutkan ke tahap selanjutnya. Dapat disimpulkan bahwa core model DSS02 hanya mencapai level 1.

Penyusunan rekomendasi perbaikan

Pada proses APO09 diperoleh tingkat kapabilitas pada level 1. Sedangkan target tingkat kapabilitas yang harus dipenuhi pada level 4. Maka dari itu, dibuat rekomendasi perbaikan pada proses APO09 pada tingkat kapabilitas di level 2. Berikut merupakan tabel rekomendasi untuk dapat mencapai tingkat kapabilitas proses level 2 pada APO09, yakni Menganalisis ketentuan dalam melakukan perjanjian terhadap layanan baru. Pertimbangkan sudut pandang seperti waktu layanan, ketersediaan, kinerja, dan lain-lain. Adapun hasil yang diperlukan adalah Dokumen SLA (Service Level Agreement).

Pada proses APO12 diperoleh tingkat kapabilitas pada level 1 . Sedangkan target tingkat kapabilitas yang harus dipenuhi pada level 4. Maka dari itu, dibuat rekomendasi perbaikan pada proses APO12 pada tingkat kapabilitas di level 2. Berikut merupakan tabel rekomendasi untuk dapat mencapai tingkat kapabilitas proses level 2 pada APO09 yakni Menggabungkan skenario risiko saat ini berdasarkan kategori. Adapun hasil yang diperlukan adalah Dokumen risk assessment.

Pada proses APO13 diperoleh tingkat kapabilitas pada level 1. Sedangkan target tingkat kapabilitas yang harus dipenuhi pada level 4. Maka dari itu, dibuat rekomendasi perbaikan pada proses APO13 pada tingkat kapabilitas di level 2. Berikut 
merupakan tabel rekomendasi untuk dapat mencapai tingkat kapabilitas proses level 2 pada APO13, yakni Mendapatkan kepemilikan manajemen agar dapat menerapkan serta menjalankan mengubah ISMS; menyiapkan dan menjaga pernyataan dokumen yang menjelaskan area ISMS. Adapun hasil yang diperlukan adalah dokumen risk assessment.

Pada proses DSS02 diperoleh tingkat kapabilitas pada level 1. Sedangkan target tingkat kapabilitas yang harus dipenuhi pada level 4 . Maka dari itu, dibuat rekomendasi perbaikan pada proses DSS02 pada tingkat kapabilitas di level 2. Berikut merupakan tabel rekomendasi untuk dapat mencapai tingkat kapabilitas proses level 2 pada DSS02, yakni Untuk mengaktifkan analisis tren, klasifikasikan permintaan dan perihal layanan dengan mengidentifikasi jenis dan kategori; Memilih permintaan yang dianggap nilai prioritasnya tinggi dan insiden layanan berdasarkan layanan SLA tentang dampak dan urgensi bisnis; Melakukan verifikasi dalam wewenang untuk permintaan layanan; Tutup permintaan dan insiden layanan. Adapun hasil yang diperlukan adalah dokumen incident priority

\section{Kesimpulan}

Berdasarkan hasil penelitian terdapat kesimpulan yang diperoleh, yaitu:

1. Hasil dari perancangan manajemen TI menggunakan framework COBIT 2019 diperoleh core model yang penting bagi PT XYZ Balikpapan dengan masingmasing core model memiliki nilai lebih dari 75 dengan masingmasing tingkat kapabilitas pada level 4. Adapun core model diantaranya yaitu APO09 Managed Service Agreements, APO12 Managed Risk, APO13 Managed Security, dan DSS02 Managed Service Requests \& Incidents.
2. Memberikan rekomendasi berdasarkan penilaian tingkat kapabilitas pada 4 core model yaitu APO09 Managed Service Agreements berada di level 1, APO12 Managed Risk berada di level 1, APO13 Managed Security berada di level 1, dan DSS02 Managed Service Requests \& Incidents berada di level 1. Dari 4 core model yang disebutkan belum mencapai target tingkat kapabilitas, dimana semua target tingkat kapabilitasnya berada di level 4. Maka, dilakukan semua aktivitas pada proses APO09 Managed Service Agreements agar dapat mencapai target tingkat kapabilitas di level 4, serta proses ini memiliki nilai prioritas paling tinggi sebesar 100. Setelah dilakukan semua aktivitas pada APO09, maka menghasilkan dokumen analisis kebutuhan kapasitas masa yang akan datang, service catalog, dan service level agreement. Telah disusun dokumen rekomendasi analisis kebutuhan kapasitas mendatang, service catalog, dan service level agreement yang diperiksa dan diverifikasi oleh Bidang Dukungan dan Operasi, dengan adanya dokumen ini diharapkan level kapabilitas pada core model APO09 Managed Service Agreements mencapai level kapabilitas yang diharapkan.

3. Evaluasi penilaian tingkat kematangan yang ada pada penelitian ini hanya dilakukan pada proses yang memiliki target capability level 4 yaitu diantaranya APO09 (Managed Service Agreements), APO12 Managed Risk, APO13 Managed Security, dan DSS02 Managed Service Requests \& Incidents. Oleh karena itu, diharapkan pada penelitian selanjutnya dapat dilakukan evaluasi pada semua proses core model. 


\section{Daftar Pustaka}

Alreemy, Z., Chang, V., Walters, R., \& Wills, G. (2016). Critical success factors (CSFs) for information technology governance (ITG). International Journal of Information Management, 36(6), 907-916.

https://doi.org/10.1016/j.ijinfom gt.2016.05.017

Azara, R. (2020). Buku Ajar Manajemen Operasional Dan Implementasi Dalam Industri. In Buku Ajar Manajemen Operasional Dan Implementasi Dalam Industri. https://doi.org/10.21070/2020/9 78-623-6833-48-3

Bayastura, S. F., Krisdina, S., \& Widodo, A. P. (2021). Analysis and Design of Information Technology Governance Using the Cobit 2019 At Pt . Xyz. Jiko, 4(1), 68-75. https://doi.org/10.33387/jiko

Belo, G. I., Wiranti, Y. T., \& Atrinawati, L. H. (2020). Perancangan Tata Kelola Teknologi Informasi Menggunakan Cobit 2019 Pada PT Telekomunikasi Indonesia Regional VI Kalimantan. JUSIKOM PRIMA (Jurnal Sistem Informasi Ilmu Komputer Prima), 4(1), 2330.

ISACA. (2018). COBIT ${ }^{\circledR} 2019$ Framework: Introduction \& Methodology.

ISACA. (2019). COBIT 2019 Framework: Governance and Management Objectives.

IT Governance Institute (ITGI). (2007). COBIT 4.1: Framework, Control Objectives, Management Guidelines, Maturity Models. In Governance An International Journal of Policy And Administration.

Karkoskova, S., \& Feuerlicht, G. (2015).
Extending MBI Model using ITIL and COBIT Processes. Journal of Systems Integration, October, 2944.

https://doi.org/10.20470/jsi.v6i4. 244

Mariatama, A. A. (2021). Perancangan Tata Kelola Teknologi Informasi dengan Menggunakan Framework COBIT 2019 pada PT JWT Global Logistics Indonesia. Institut Teknologi Kalimantan.

Maulana Fikri, A., Shofia Priastika, H., Octaraisya, N., Happy Trinawati, L., Kalimantan, T., Soekarno-Hatta Km, J., Joang, K., \& Timur, K. (2020). Rancangan Tata Kelola Teknologi Informasi Menggunakan Framework COBIT 2019 (Studi Kasus: PT XYZ). Information Management for Educators and Professionals, 5(1), 1-14.

https://doi.org/10.51211/imbi.v5i 1.1410

Miranti, A. (2019). Evaluasi Tata Kelola Teknologi Informasi Menggunakan Framework COBIT 5 (Studi Kasus : PT Praweda Ciptakarsa Informatika). In Universitas Islam Negeri Syarif Hidayatullah (Vol. 53, Issue 9).

Novita Anastasia, P., \& Happy Atrinawati, L. (2020). Perancangan Tata Kelola Teknologi Informasi Menggunakan Framework Cobit 2019 Pada Hotel Xyz. JSI : Jurnal Sistem Informasi (E-Journal), 12(2), 2020.

http://ejournal.unsri.ac.id/index.p $\mathrm{hp} / \mathrm{jsi} /$ index

Prasetyo, A., \& Mariana, N. (2011). Analisis Tata Kelola Teknologi Informasi ( It Governance ) pada Bidang Akademik dengan Cobit Frame Work Studi Kasus pada Universitas Stikubank Semarang. Jurnal Teknologi Informasi DINAMIK, 16(2), 139-149. 
Richardus Eko Indrajit. (2014). Manajemen Organisasi dan Tata Kelola Teknologi Informasi. Aptikom.

Sinta, P. H., Swastika, I. P. A., \& Raditya Putra, I. G. L. A. (2019). Evaluasi Tata Kelola Teknologi Informasi berbasis COBIT 5 pada Badan Pendapatan Daerah Kabupaten Badung. Jurnal Teknologi Dan Ilmu Komputer Prima (JUTIKOMP), 2(2), 1. https://doi.org/10.34012/jutikom p.v3i1.647

Solehuddin, M., Hulwani, Z., Widodo, P., Informasi, S., Pascasarjana, S., Mengelola, B. A. I., Pende, M., \& Manajemen, B. A. I. (2021). Perencanaan Tata Kelola Teknologi Informasi Menggunakan Framework Cobit 2019 pada
DPMPTSP. 20, 155-164.

Supangat, R., Kom, S., \& Kom, M. (2022). Analisis Tingkat Kematangan Dan Perancangan Peningkatan Layanan Sistem Informasi Rektorat Universitas 17 Agustus 1945 Surabaya.

Tri Oktarina. (2017). Tata Kelola Teknologi Informasi Dengan Cobit 5. Jurnal Informanika, 4(2), 9-15.

Wahono, B. B. (2015). Perancangan Tatakelola Teknologi Informasi Untuk Peningkatan Layanan Sistem Informasi Kesehatan (Studi Kasus Dinas Kesehatan Kabupaten Jepara). Simetris : Jurnal Teknik Mesin, Elektro Dan Ilmu Komputer, 6(1), 101. https://doi.org/10.24176/simet.v 6i1.244 